\title{
Trace element speciation in toxicology and clinical sciences
}

\begin{abstract}
D.M. Templeton
The importance of species-selective information in the biomedical field is discussed. The issues disucussed include the toxicity of inorganic and organometallic compounds and effects of oxidation state, the role of metal based drugs and metal-compounds in therapy, and the role of metal-binding biomacromolecules and low molecular mass metal complexes in the transport and storage of metal ions.
\end{abstract}

peciation analysis, the determination of the concentrations of separate and unique atomic and molecular forms of an element instead of its total concentration in a sample, is now a frequent and fruitful exercise in many scientific disciplines. It has become important in human biology, nutrition, and toxicology; in clinical practice more generally it has yet to do so, and there may be an opportunity to introduce speciation analysis into the medical laboratory's armamentarium. However, concentrations of essential, endogenous elements are frequently controlled homeostatically, and instances of pathology arising from altered speciation of these elements are relatively rare. Even when a major ligand is deficient (e.g., a deficiency of the copper-binding protein caeruloplasmin in Wilson disease) it is the total concentration of the element, rather than its distribution among species, that is of most diagnostic significance. On the other hand, speciation profoundly influences both the toxicity and bioavailability of an element. Exposures to some forms of an element may be harmless, while other species of the same element can be toxic, carcinogenic, or mutagenic (e.g., $\mathrm{Cr}$ (III) is an essential element but salts of $\mathrm{Cr}(\mathrm{VI})$ are carcinogenic). Inorganic forms of toxic metals frequently target the kidney (e.g., $\mathrm{Hg}^{2+}$ ), while organometallic forms of the same element can cross the blood-brain barrier by virtue of their lipohilicity and become potent neurotoxins $\left(\mathrm{CH}_{3} \mathrm{Hg}^{+}\right)$. Absorption from the diet (e.g., the greater bioavailability of heme-iron than $\mathrm{Fe}^{3+}$ salts, or the solubilization of $\mathrm{Al}^{3+}$ by dietary citrate) and ultimate fate in the body (e.g., Se from selenocysteine vs. selenite) are determined by speciation. Speciation also determines how metals enter cells (e.g., $\mathrm{Cd}^{2+}$ salts may enter through $\mathrm{Ca}^{2+}$ channels, whereas $\left[\mathrm{Cd}(\mathrm{OH})\left(\mathrm{HCO}_{3}\right)_{2}\right]^{-}$can be internalized through anion transporters in erythrocytes), and complexation with the same ligand (e.g., histidine) may increase the cellular uptake of some metals ions $\left(\mathrm{Cu}^{2+}\right)$ and decrease that of others $\left(\mathrm{Ni}^{2+}\right)$.

It is clear from the foregoing comments that determining the species distribution of an element during occupational exposure, in the diet, or in an environmental sample is fre- quently useful. Often the same exogenous species will be measured untransformed in a biological fluid or tissue in order to assess the original exposure. On the other hand, changes in speciation that occur in the body will generally be an indication of the extent to which metabolic detoxification is occurring. Special instances where speciation becomes important in medicine include the administration of metal-based therapeutic agents, radionuclide imaging agents, and radiographic contrast agents; and in the use of chelating agents to mobilize metals from endogenous sources. And of course we cannot be said to understand the biology of an element until we know how it is distributed among its various chemical species in different body compartments. Below we will discuss examples of several areas in which considering speciation has contributed to our understanding of the interaction of metal and metalloid elements with the human organism.

\section{Toxicity of inorganic compounds}

A number of toxic metals of industrial importance are associated with toxic effects that include target organ damage, carcinogenicity, and potential teratogenicity. The rich inorganic chemistry of these elements produces species with widely divergent biological properties. Many such metals are only biotransformed by humans to a limited extent, and it is therefore their speciation before entering the body that is of interest in occupational health. These concepts are well illustrated by $\mathrm{Ni}$ compounds [1]. For example, in some refining operations workers may encounter $\mathrm{Ni}_{3} \mathrm{~S}_{2}, \mathrm{NiO}, \mathrm{Ni}^{0}, \mathrm{Ni}-\mathrm{Cu}$ oxides, $\mathrm{Ni}-\mathrm{Fe}$ oxides, $\mathrm{NiSO}_{4}, \mathrm{NiCl}_{2}$, and $\mathrm{NiCO}_{3}$. Whereas $\mathrm{Ni}_{3} \mathrm{~S}_{2}$ is a potent carcinogen in animals, $\mathrm{NiCl}_{2}$ is of very low toxicity. This may be because the relatively insoluble subsulfide is phagocytosed in particulate form, resulting ultimately in very high local intracellular concentrations, whereas the Ni salt is readily excreted by the kidney. The solubility of the species is an important factor in determining its biokinetics, and is therefore of importance in biological monitoring. For example, appropriately timed measurements of $\mathrm{Ni}$ in serum or urine will reflect short-term occupational exposures to soluble $\mathrm{Ni}$ salts but not to $\mathrm{Ni}$ oxides. The International Agency for Research on Cancer has concluded that $\mathrm{NiSO}_{4}$ and combinations of $\mathrm{Ni}$ sulfides and oxides are carcinogenic in humans; in addition, $\mathrm{Ni}$ hydroxides and crystalline sulfides are carcinogenic in animals. However, there is limited evidence for the carcinogenicity of $\mathrm{Ni}(\mathrm{CO})_{4}, \mathrm{Ni}$ salts, arsenides, and selenides; and inadequate evidence for the carcinogenicity of $\mathrm{Ni}_{2} \mathrm{O}_{3}$ and amorphous Ni sulfides [1]. Clearly, measuring total $\mathrm{Ni}$ on an air filter in the workplace without speciation analysis will convey little about risk. 
Hydroxide is a dominant inorganic ligand determining the biological behaviour of an element. Metal complexes may dissociate in the stomach $(\mathrm{pH} \approx 1)$ but upon passage into the duodenum and/or absorption into the blood $(\mathrm{pH} \approx 7.4)$ will combine with new sets of ligands. For essential elements (e.g., $\mathrm{Fe}(\mathrm{OH})_{3}, \mathrm{Ksp} \approx 10^{-38}$ ), this requires biological fluids of appropriate composition for complexation with organic and macromolecular ligands, and has determined the evolution of careful mechanisms of chaperoning metals from one cellular target to another. On the other hand, in the absence of competitive ligands for non-essential elements, hydrolysis to the insoluble $\mathrm{M}^{n+}(\mathrm{OH})_{n}$ may limit their availability and toxicity. This is the case for $\mathrm{Al}^{3+}$, for instance, whose absorption can nevertheless be greatly increased by co-ingestion of citric acid. Organometallic compounds: As noted above, alkylation of metals can produce neurotoxic species of environmental significance. Important examples include $\mathrm{Pb}, \mathrm{Sn}$, and $\mathrm{Hg}$. Organometallic pollutants may be anthropogenic in origin, as when synthetic organoleads are added to gasoline to improve the octane rating and subsequently enter the atmosphere as exhaust emissions. Likewise, synthetic organotins are released into the environment in significant amounts from their use as antifouling agents. These include tri- and tetra-alkyl and phenyl tins. On the other hand, $\mathrm{Hg}^{2+}$ undergoes bioalkylation in the environment. Microorganisms in soils and sediments monomethylate the ion and $\mathrm{CH}_{3} \mathrm{Hg}^{+}$ accumulates in the food chain, notably in fish and shellfish. These organomercurials are not metabolized further in the human body. For toxicological assessment, the important problem is to distinguish organic from inorganic forms of the metal. $\mathrm{Pb}, \mathrm{Sn}, \mathrm{Sb}, \mathrm{Ni}$, and $\mathrm{Ge}$ also undergo environmental bioalkylation reactions in microorganisms, by far the most important of which are methylations [2]. The important biological methyl donors are S-adenosylmethionine and methyl cobalamin. The former transfers a methyl carbocation from a sulfonium ion to a nucleophilic acceptor such as selenide. Methyl cobalamin, in contrast, transfers a methyl carbanion to electrophilic substrates, and is the biological methyl donor for $\mathrm{Hg}^{2+}$.

In contrast to the metals, the metalloids As and Se undergo alkylation reactions in a wide range of organisms, including man, and these reactions produce species with decreased toxicity. The essential element Se is discussed further below. The speciation of As in man reflects both the species taken in from the environment and metabolites produced in the body. Arsenate reductase reduces arsenate $\left(\mathrm{AsO}_{4}^{3-}\right)$ to arsenite $\left(\mathrm{AsO}_{3}^{3-}\right)$, and then sequential action of two $\mathrm{S}$-adenosylmethionine-dependent enzymes produces monomethylarsonate $\left(\mathrm{CH}_{3} \mathrm{AsO}_{3}^{-}\right)$and dimethylarsinate $\left[\left(\mathrm{CH}_{3}\right)_{2} \mathrm{AsO} \cdot \mathrm{OH}\right]$, the major metabolites in man. They are indicators of exposure to toxic environmental inorganic As. Other organisms synthesize arsenosugars from which are derived arsenobetaine and arsenocholine. These species are frequently a significant portion of total blood As in man and generally represent ingestion from seafood. These species are non-toxic. Therefore, for meaningful exposure monitoring, it is necessary to measure inorganic forms of As(III) and $\mathrm{As}(\mathrm{V})$ after separation from organic forms, and to distinguish mono- and dimethylated species from non-toxic environmental organoarsenicals [3].

\section{Effects of oxidation state}

The valence state of an element can profoundly affect its toxicity. $\mathrm{Cr}$ (III) is believed by many to be an essential element required for normal glucose metabolism but $\mathrm{Cr}(\mathrm{VI})$ is genotoxic and carcinogenic [4]. $\mathrm{Cr}^{6+}$ does not itself bind to DNA but is reduced to $\mathrm{Cr}^{3+}$ which does. The binding of $\mathrm{Cr}^{3+}$ is insufficient to damage DNA in vitro and it is supposed that damage results from intermediate valence states of $\mathrm{Cr}$ arising during the reduction process. Speciation analysis of $\mathrm{Cr}$ valence states is of more interest before $\mathrm{Cr}$ enters the body; once inside the cell the reduction of $\mathrm{Cr}(\mathrm{VI})$ is rapid and total $\mathrm{Cr}$ levels may indicate the potential for damage to have been done.

Oxidation state is also a critical determinant of cellular uptake and trafficking of metals. Chromium(VI) is taken up by many cells as chromate $\left(\mathrm{CrO}_{4}^{2-}\right)$ utilizing anion transporters, whereas $\mathrm{Cr}^{3+}$ salts permeate the lipid membrane with difficulty. Iron is frequently transported across plasma membranes or intracellular barriers by reduction of $\mathrm{Fe}^{3+}$ to $\mathrm{Fe}^{2+}$ with subsequent reoxidation, exploiting the higher transport coefficient and lesser hydrolysis of the ferrous ion. The conversion of $\mathrm{Hg}$ (II) salts to $\mathrm{Hg}^{0}$ is carried out by mercuric reductases that act to detoxify $\mathrm{Hg}$, since volatile $\mathrm{Hg}^{0}$ diffuse freely out of the cell and is lost [5]. A similar enzyme is inducible by ethanol in human liver.

\section{Metal-based drugs}

Common examples of metal-based therapies are the use of $\mathrm{Au}$ compounds in chrysotherapy for arthritis and Pt compounds as antitumor agents. Once inside the body, formation of new species determine biological activity. Cisplatin [cis$\mathrm{Pt}(\mathrm{II}) \mathrm{Cl}_{2}\left(\mathrm{NH}_{3}\right)_{2}$ ] is activated upon entry into cells where $\mathrm{Cl}-$ concentration is only about $3 \mathrm{mM}$. The complex is aquated and the equilibrium $\mathrm{Pt}\left(\mathrm{NH}_{3}\right)_{2}\left(\mathrm{H}_{2} \mathrm{O}\right)_{2}^{2+} \rightleftharpoons$ $\mathrm{Pt}\left(\mathrm{NH}_{3}\right)_{2}(\mathrm{OH})\left(\mathrm{H}_{2} \mathrm{O}\right)^{+}$is established. These species are involved in forming DNA adducts and cross-links. Drug efficacy itself is species-dependent, the trans isomer being much less cytotoxic. In practice, however, the individual Pt species are not measured during therapy.

A number of metal-based reagents are used in diagnostic imaging. These include radioactive emitters like ${ }^{99 \mathrm{~m}} \mathrm{Tc}$ and ${ }^{67} \mathrm{Ga}$, radio-opaque $\mathrm{Ba}$ compounds, and paramagnetic relaxation reagents like $\mathrm{Gd}^{3+}$ salts for magnetic resonance imaging. Speciation is a key determinant of the biological fate of the element, and hence of the interpretation of the resulting diagnostic images. This is illustrated by ${ }^{67} \mathrm{Ga}[6] .{ }^{67}$ Galliumcitrate is used as a tumor imaging agent whose speciation in blood plasma has been studied by computer modeling. The relative importance of the low molecular mass fraction and the predominance of $\mathrm{Ga}(\mathrm{OH})_{4}^{-}$in this fraction are predicted to be comparable whether ${ }^{67} \mathrm{Ga}$ is injected as the citrate complex or not. Slow association with transferrin affects speciation at later times. The computed speciation is consistent with the biokinetic behaviour of the radiotracer. The low molecular mass species account for early excretion and later tissue deposition involves transferrin-bound Ga. However, uptake by tumor tissue may involve non-transferrin-bound ion. Consistent with this, a 10-fold increase in the low mol- 
ecular mass fraction predicted in hypotransferrinemic serum correlates with the increased uptake by tumor in tumor-bearing hypotransferrinemic mice. Clinical hypotheses regarding the role of local increase in $\left[\mathrm{Ca}^{2+}\right]$ or decrease in $\mathrm{pH}$ in releasing $\mathrm{Ga}$ from transferrin are not borne out by speciation calculations.

\section{Chelation therapy}

Chelating agents are used clinically to remove toxic metals such as $\mathrm{Pb}, \mathrm{Hg}$, and $\mathrm{Al}$ from the body. By definition, they effect a change in speciation. While the object is to enhance excretion of the metal, careful consideration of speciation is necessary to avoid unwanted effects. Formation of lipophilic $\mathrm{Pb}$ complexes may facilitate transport of $\mathrm{Pb}$ across the blood-brain barrier and increase neurotoxicity, and mobilization of water-soluble complexes of $\mathrm{Cd}$ from the liver can damage the kidney. Chelation of $\mathrm{Fe}$ from thalassemic patients undergoing repeated blood transfusions is only approved using lifelong daily parenteral infusion of the hexadentate chelator, deferoxamine. This has driven ongoing attempts to develop an orally effective Fe chelator, and considerations of speciation have been central in designing such agents. Deferiprone (1,2-dimethyl-3-hydroxypyridin-4-one) is undergoing clinical trials as an orally available $\mathrm{Fe}^{2+}$ chelator in these patients. Speciation of the Fe(III)-deferiprone system has been studied by potentiometry [7]. Deferiprone is a bidentate chelator with an overall $\log \beta 3$ for the $3: 1$ complex of 35.9 but for the addition of the third ligand (log $\beta 3-\log \beta 2$ ) only 9.2. At $\mathrm{pH} \mathrm{7,} \mathrm{a} 1 \mathrm{mM}$ solution of the complex with ligand in excess contains nearly exclusively the $\mathrm{L}_{3} \mathrm{Fe}$ species, but at $1 \mu \mathrm{M}$ approximately equal amounts of $\mathrm{L}_{3} \mathrm{Fe}$ and $\mathrm{L}_{2} \mathrm{Fe}\left(\mathrm{H}_{2} \mathrm{O}\right)^{2+}$ complexes exist. There is concern whether the incompletely coordinated species will allow access of peroxide to the Fe center and function more effectively as a Fenton catalyst, generating harmful $\mathrm{HO}^{*}$ in the patient. Allowing concentrations of the drug to fall may actually be more dangerous than maintaining relatively high levels, because of changes in speciation.

\section{Metal-binding macromolecules}

Most metals exist in biological fluids mainly in macromolecular form in equilibrium with a small, poorly defined, low molecular mass fraction. Essential elements like $\mathrm{Fe}, \mathrm{Cu}, \mathrm{Zn}$, and $\mathrm{Mn}$ are distributed among many dozens of enzymes where they provide structure, are redox active, or act as Lewis acids. By their nature, enzymes are generally present in catalytic amounts, and measurement of individual enzymes is not usually part of biological speciation analysis. Rather, the macromolecular metal fraction is dominated by relatively few transport or storage proteins present in relatively greater amounts. Albumin is the protein present in blood plasma at the highest concentration, approximately $1 \mathrm{mM}$. Therefore, for non-essential elements without specific binding sites on other proteins, non-specific binding to albumin may dominate speciation in the blood by mass action. This is true for instance of $\mathrm{Cd}^{2+}$. On the other hand, the $\mathrm{Fe}^{3+}$ transport protein transferrin has two specific iron-binding sites with association constants of about $10^{20}$, and is the exclusive Fe species in normal human plasma on thermodynamic grounds. Other trivalent metals like $\mathrm{Al}^{3+}$ and $\mathrm{Ga}^{3+}$ also bind tightly at these sites. Time-dependent partitioning of $\mathrm{Cr}$ (III) between albumin and transferrin determine its rate of absorption from dialysis fluid in patients undergoing renal dialysis.

About $65 \%$ of $\mathrm{Cu}$ in plasma is bound irreversibly to caeruloplasmin, a $\mathrm{Cu}$ oxidase involved in $\mathrm{Fe}$ transport. A lesser amount $(\approx 15 \%)$ is bound to the $\mathrm{N}$-terminal tripeptide of albumin, a specific binding site it shares with $\mathrm{Ni}^{2+}$. Another $15 \%$ of plasma $\mathrm{Cu}$ is bound to a large protein of unknown function called transcuprein [8]. All three species probably contribute to $\mathrm{Cu}$ transport. The remaining $5 \%$ is in low molecular mass complexes. $\mathrm{Zn}^{2+}$ too is mainly macromolecule-bound in plasma, with albumin as the major species and $\alpha_{2}$-macroglobulin accounting for about $30 \%$. Ternary complexes with small molecules (chiefly amino acids) and albumin probably also occur, as $\mathrm{Zn}^{2+}$ is not fully coordinated at the $\mathrm{N}$-terminal $\mathrm{Cu}^{2+}$-binding site, but rather binds elsewhere in the molecule. Therefore, $\mathrm{Cu}^{2+}$ and $\mathrm{Zn}^{2+}$ do not share a common site on albumin, caeruloplasmin does not bind $\mathrm{Zn}^{2+}$, and $\alpha_{2}$-macroglobulin does not bind $\mathrm{Cu}^{2+}$; and probably the ions have a different preferences for cysteine $\left(\mathrm{Zn}^{2+}\right)$ and histidine $\left(\mathrm{Cu}^{2+}\right)$ in their low molecular mass amino acid complexes. This limits the interactions of these two essential elements [9], which are both homeostatically regulated at about $1 \mu \mathrm{g} / \mathrm{mL}$ in plasma and have the potential for significant mutual interference.

In tissues, metallothionein is an important species for a number of metal ions. In man, this low molecular mass protein $($ c.a. $6 \mathrm{kDa})$ contains 20 cysteine residues, all in the reduced state in the native protein. The sulfhydryl groups bind seven atoms of $\mathrm{Cd}^{2+}$ or $\mathrm{Zn}^{2+}$ in polynuclear clusters, and somewhat higher stoichiometries of $\mathrm{Hg}^{2+}$ and $\mathrm{Cu}$ as $\mathrm{Cu}(\mathrm{I})$. Each of these metals induces the transcription of the metallothionein gene, allowing the protein to function in the detoxification of $\mathrm{Cd}^{2+}$ and $\mathrm{Hg}^{2+}$ and the storage of $\mathrm{Cu}^{+/ 2+}$ and $\mathrm{Zn}^{2+}$ [10]. Other metal ions will also bind to apothionein in vitro. Although a major ligand in tissues, metallothionein does not usually achieve significant concentrations in extracellular fluids.

\section{Selenium}

Among metals and metalloids, Se displays unique speciation chemistry in humans because we incorporate it with covalent $\mathrm{C}$-Se bonds into the seleno analogs of the amino acids cysteine and methionine, where it replaces sulfur. Metabolism and speciation are further complicated because we take in several organic and inorganic Se species with different oxidation states and biotransform them through detoxification pathways, in addition to biosynthesizing selenocysteine and selenomethionine for incorporation into proteins. Species separated in urine include selenomethionine, trimethyl selenonium ion $\left[\left(\mathrm{CH}_{3}\right)_{3} \mathrm{Se}^{+}\right]$, selenite $\left(\mathrm{SeO}_{3}^{2-}\right)$, selenate $\left(\mathrm{SeO}_{4}^{2-}\right)$, selenocholine, and various selenoproteins. The major forms in blood and plasma are proteins into which have been incorporated selenoaminoacids. In the erythrocyte, most $\mathrm{Se}$ is in hemoglobin and glutathione peroxidase (GPX). In plasma, it is found in albumin, selenoprotein P, and GPX [11]. The species distribution depends on the form of $\mathrm{Se}$ 
ingested, as well as on the animal species. In the human erythrocyte, intake of selenomethionine in foodstuffs results in most Se being incorporated into hemoglobin whereas following mineral supplementation with selenite more is in GPX. Selenate produces a roughly equal distribution. Speciation is important in interpreting Se status. For example, erythrocyte Se in Oregon residents is about three times higher than that in New Zealanders, but the latter do not show signs of Se deficiency. GPX activity is the same in both populations and both produce GPX with a similar Se content. Hemoglobin Se is higher in the Oregon population, and this is probably irrelevant for health. Selenium in hemoglobin and albumin is selenomethionine and probably represents an inconsequential substitution for methionine, whereas selenoprotein P and GPX contain selenocysteine and are probably true selenoproteins requiring Se for their function [11]. GPX is important in antioxidant defenses. Selenoprotein $\mathrm{P}$ is a glycoprotein of about $50 \mathrm{kDa}$ containing 10 selenocysteine residues. Its function is unknown, but it may also have a protective antioxidant role. A role in $\mathrm{Hg}^{2+}$ detoxification has also been suggested.

\section{Low-molecular-mass metal complexes}

Low molecular mass fractions of metals in biological fluids are generally harder to define. For some years attempts have been made to computer model the speciation of elements in biological fluids based on potentiometrically determined stability constants of isolated systems [12]. However, the large number of $\mathrm{N}-, \mathrm{O}-$, and $\mathrm{S}$-ligands available in biological fluids compromises the predictive utility of compiled stability constant data; the species distribution of an element among low molecular mass ligands such as amino and organic acids in vivo is never completely known. Citrate is present in the $\mathrm{mM}$ concentration range in plasma and is probably the major complex of $\mathrm{Fe}^{3+}$ when transferrin binding capacity becomes saturated in iron-overload disorders. Dietary citrate enhances the absorption of $\mathrm{Al}^{3+}$. On the other hand, computer modeling of low molecular mass fractions of $\mathrm{Cu}^{2+}$ and $\mathrm{Zn}^{2+}$ predicts bis amino acid complexes to predominate, with cysteine more important for $\mathrm{Zn}^{2+}$ and histidine for $\mathrm{Cu}^{2+}$. More recent attempts to model speciation of metals in body fluids have begun to include kinetic modeling in addition to thermodynamic data [12], underscoring the complexity of the in vivo situation.

\section{References}

1. IARC Monographs on the Evaluation of Carcinogenic Risks to Humans. Vol. 49: Chromium, Nickel and Welding, IARC, Lyons, 1990.

2. Thayer, J. S. in: Metal Ions in Biological Systems. Vol. 29. Biological Properties of Metal Alkyl Derivatives, Sigel, H.; Sigel, A. Eds., Marcel Dekker, New York, 1993; pp 1-36.

3. Aitio, A.; Hakal, E.; Pyy, L. in: Biological Monitoring of Chemical Exposure in the Workplace. Vol. 2, Ed., World Health Organization, Geneva, 1996; pp 18-34.

4. Katz, S. A.; Salem, H. The Biological and Environmental Chemistry of Chromium, VCH Publishers, New York, 1994.

5. Walsh, C. T.; Distefano, M. D.; Moore, M. J.; Shewchuk, L. M.; Verdine, G. L. Faseb J. 1988, 2, 124-138.

6. Jackson, G. E.; Byrne, M. J. J. Nucl. Med. 1996, 37, 379-386.

7. Motekaitis, R. J.; Martell, A. E. Inorg. Chim. Acta 1991, 183, 71-80.

8. Wirth, P. L.; Linder, M. C. JNCI 1985, 75, 277-283.

9. Bremner, I.; Beattie, J. H. Proc. Nutr. Soc. 1995, 54, 489-499.

10. Templeton, D.M. ; Cherian, M.G. Methods Enzymol. 1991, $205,11-24$.

11. Whanger, P. D.; Xia, Y.; Thomson, C. D. J. Trace Elem. Electr. Hlth. Dis. 1994, 8, 1-7.

12. May, P. in: Handbook of Metal-Ligand Interactions in Biological Fluids: Bioinorganic Chemistry, Berthon, G.; Ed. Marcel Dekker, New York, 1995; pp 1291-1297. 